\title{
The scientific report guiding the US dietary guidelines: is it scientific?
}

\author{
It has a big impact on the diet of American citizens, and those of most Western nations, so why \\ does the expert advice underpinning US government dietary guidelines not take account of all the \\ relevant scientific evidence? Nina Teicholz reports
}

Nina Teicholz journalist, New York City, USA

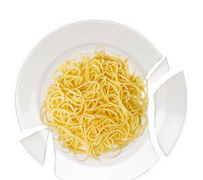

The expert report underpinning the next set of US Dietary Guidelines for Americans fails to reflect much relevant scientific literature in its reviews of crucial topics and therefore risks giving a misleading picture, an investigation by The $B M J$ has found. The omissions seem to suggest a reluctance by the committee behind the report to consider any evidence that contradicts the last 35 years of nutritional advice.

Issued once every five years, the guidelines have a big influence on diet in the US, determining nutrition education, food labeling, government research priorities at the National Institutes of Health, and public feeding programs, which are used by about a quarter of Americans each year. ${ }^{1}$ The guidelines, which were first issued in 1980, have also driven nutrition policy globally, with most Western nations subsequently adopting similar advice.

The guidelines are based on a report produced by a dietary guidelines advisory committee-a group of 11-15 experts who are appointed to review the best and most current science to make nutrition recommendations that both promote health and fight disease. The committee's latest report was published in February ${ }^{2}$ and is under review by the government's health and agricultural agencies, which will finalize the guidelines in the fall.

Concern about this year's report has been unprecedented, with some 29000 public comments submitted compared with only 2000 in 2010. In recent months, as government officials convert the scientific report into the guidelines, Congress has sought to intervene. In June, it proposed a requirement that the guidelines be based exclusively on "strong" science and also that they focus on nutritional concerns without consideration of sustainability. Other debated topics include newly proposed reductions in consumption of sugar and red meat.

These issues will likely come to a head at a Congressional hearing on the guidelines in October, when two cabinet secretaries are scheduled to testify.

The $B M J$ has also found that the committee's report used weak scientific standards, reversing recent efforts by the government to strengthen the scientific review process. This backsliding seems to have made the report vulnerable to internal bias as well as outside agendas.

The 2015 report states that the committee abandoned established methods for most of its analyses. Since its inception, the guideline process has suffered from a lack of rigorous methods for reviewing the science on nutrition and disease, but a major effort was undertaken in 2010 to implement systematic reviews of studies to bring scientific rigor and transparency to the review process. The US Department of Agriculture set up the Nutrition Evidence Library (NEL) to help conduct systematic reviews using a standardized process for identifying, selecting, and evaluating relevant studies. ${ }^{3}$

However, in its 2015 report the committee stated that it did not use NEL reviews for more than $70 \%$ of the topics, including some of the most controversial issues in nutrition. ${ }^{4}$ Instead, it relied on systematic reviews by external professional associations, almost exclusively the American Heart Association (AHA) and the American College of Cardiology (ACC), or conducted an hoc examination of the scientific literature without well defined systematic criteria for how studies or outside review papers were identified, selected, or evaluated.

Use of external reviews by professional associations is problematic because these groups conduct literature reviews according to different standards and are supported by food and drug companies. The ACC reports receiving $38 \%$ of its revenue from industry in 2012, and the AHA reported $20 \%$ of revenue from industry in 2014. Potential conflicts of interest include, for instance, decades of support from vegetable oil 
manufacturers, whose products the AHA has long promoted for cardiovascular health. This reliance on industry backed groups clearly undermines the credibility of the government report.

\section{Saturated fats}

On saturated fats, for example, the committee did not ask the NEL to conduct a formal review of the literature from the past five years, even though this topic clearly merited re-examination. When the committee started its work in 2012, there had been several prominent papers, including a meta-analysis ${ }^{5}$ and two major reviews (one systematic) ${ }^{67}$ that failed to confirm an association between saturated fats and heart disease.

Restrictions on saturated fats have been a foundation of nutrition policy since the first guidelines in 1980 and have had a dominant role in determining which foods, such as low fat dairy and lean meats, are considered "healthy." Instead of requesting a new NEL review for the recent literature on this crucial topic, however, the 2015 committee recommended extending the current cap on saturated fats, at $10 \%$ of calories, based on a review by the AHA and ACC, ${ }^{8}$ a 2010 NEL review, and the 2015 committee's ad hoc selection of seven review papers (see table A on thebmj.com). ${ }^{9}$

The NEL systematic review on saturated fats from $2010^{10}$ covers only the literature published from 2004 to 2009, the period which the 2010 committee had been asked to review. Fewer than 12 small trials are cited, and none supports the hypothesis that saturated fats cause heart disease (see table B on thebmj.com).

More significantly, this review omits a large controlled clinical trial, the Women's Health Initiative, which included nearly 49 000 people and achieved a significantly lower intake of saturated fat in the intervention group yet, compared with controls, observed no benefits for this group in incidence of fatal and non-fatal coronary heart disease events and total cardiovascular disease, including stroke. ${ }^{11}$

Papers on saturated fats published since 2010 were covered by the committee's ad hoc review, which did not use a systematic method to select or evaluate studies. One of the meta-analyses it cited was arguably inappropriately included because it considered polyunsaturated vegetable oils rather than saturated fats. ${ }^{12}$ Another analysis cited in great detail had already been covered by the 2010 NEL review, so including it again amounted to double counting. ${ }^{13}$ Three meta-analyses concluded that saturated fats did not increase cardiovascular mortality, ${ }^{14-16}$ but the committee downplays these findings. And two other included meta-analyses had mixed results: saturated fats generally looked more atherogenic than polyunsaturated fats but less atherogenic than carbohydrates or monounsaturated fat. ${ }^{11} 18$ Despite this conflicting evidence, however, the committee's report concludes that the evidence linking consumption of saturated fats to cardiovascular disease is "strong."

Perhaps more important are the studies that have never been systematically reviewed by any of the dietary guideline committees. ${ }^{19}$ These include the large, government funded randomized controlled trials on saturated fats and heart disease from the 1960s and '70s. Taken together, these trials followed more than 25000 people, some for up to 12 years. They are some of the most ambitious, well controlled nutrition studies ever undertaken..$^{20-25}$ These studies showed mixed health outcomes for saturated fats, but early critical reviews, including one by the National Academy of Sciences, which cautioned against the inconclusive state of the evidence on saturated fats and heart disease, were dismissed by the USDA when it launched the first dietary guidelines in $1980 .{ }^{26}$ Subsequent guideline committees have never gone back to systematically review these early trials but instead relied on other government reports.

\section{Low carbohydrate diets}

Another important topic that was insufficiently reviewed is the efficacy of low carbohydrate diets. Again, the 2015 committee did not request a NEL systematic review of the literature from the past five years. The report says that this was because, after conducting "exploratory searches" of the literature since 2000, the committee could find "only limited evidence [on] low-carbohydrate diets and health, particularly evidence derived from US based populations." ${ }^{27}$

The report provides no documentation of these "exploratory searches," yet many studies of carbohydrate restriction have been published in peer review journals since 2000, nearly all of which were in US populations. These include nine pilot studies, 11 case studies, 19 observational studies, and at least 74 randomised controlled trials, 32 of which lasted six months or longer (see table $\mathrm{C}$ on thebmj.com). A meta-analysis and a critical review have concluded that low carbohydrate diets are better than other nutritional approaches for controlling type 2 diabetes, ${ }^{28} 29$ and two meta-analyses have concluded that a moderate to strict low carbohydrate diet is highly effective for achieving weight loss and improving most heart disease risk factors in the short term (six months). ${ }^{3031}$ Weight loss benefits on different diets tended to converge over the long term (12 months), according to various reviews, but a recent meta-analysis found that if carbohydrates are kept "very low," weight loss is greater than with a low fat diet maintained for a year. ${ }^{32}$ Given the growing toll taken by these conditions and the failure of existing strategies to make meaningful progress in fighting obesity and diabetes to date, one might expect the guideline committee to welcome any new, promising dietary strategies. It is thus surprising that the studies listed above were considered insufficient to warrant a review.

\section{New strategies}

The committee's approach to the evidence on saturated fats and low carbohydrate diets reflects an apparent failure to address any evidence that contradicts what has been official nutritional advice for the past 35 years. The foundation of that advice has been to recommend eating less fat and fewer animal products (meat, dairy, eggs) while shifting calorie intake towards more plant foods (fruits, vegetables, grains, and vegetable oils) for good health. And in the past decades, this advice has remained virtually unchanged. ${ }^{33}$

Because the guidelines have obviously not led to better health, however, there has been a need to find new strategies to tackle nutrition related diseases. The committee's new proposal for a cap on sugar consumption is one idea. The committee's most significant shift, which began in 2010, however, has been to redouble its efforts towards emphasizing a plant based diet. This can be seen in a number of ways in the 2015 report, none of which is supported by strong evidence.

New proposals by the 2015 report include not only deleting meat from the list of foods recommended as part of its healthy diets, but also actively counseling reductions in "red and processed meats." ${ }^{34}$ This advice has been the subject of much debate, which guideline supporters have successfully characterized as a conflict between the self interested meat industry versus virtuous efforts to safeguard health (and the environment). ${ }^{356}$ Yet framed this way, the debate fails to address 
the question fundamental to nutrition: would reducing meat lead to better health? Consulting the NEL for a review on this topic turns up a surprising fact: a systematic review on health and red meat has not been done. Although several analyses look at "animal protein products," these reviews include eggs, fish, and dairy and therefore do not isolate the health effects of red meat, or meat of any kind. ${ }^{37}$

Importantly, some of the report's findings also contradict the dietary committee's advice on red meat. For example, to support the idea that red meat harms health, the committee repeatedly cites one large randomized trial conducted in Spain. However, this trial did not intend to lower consumption of red and processed meats in the experimental group, compared with the control group, so cannot be said to support the committee's advice. ${ }^{38}$ Also, the sole diagram on red meat in the committee's report, which plots the data from observational studies, shows a roughly equal number of health benefits associated with the diets higher in red meat as with diets lower in red meat. ${ }^{39}$

\section{Recommended diets}

Another clear move towards a plant based approach in the report is the introduction of the "healthy vegetarian diet" as one of three recommended diets (the others are: "healthy Mediterranean-style" and "healthy US-style"). ${ }^{2}$ A NEL review of a healthy vegetarian diet does exist, but it concludes that the evidence for this diet's disease fighting powers is only "limited," which is the lowest rank for available data. ${ }^{40}$ Moreover, although the NEL conducted eight reviews on fruits and vegetables, none found strong (grade 1) evidence to support the assertion that these foods can provide health benefits. ${ }^{41}$

In general, the quality of the evidence supporting the report's three recommended diets is limited (table D on the bmj.com). The committee could find only "limited" to "not assignable" evidence to show that its diets protect against osteoporosis, congenital abnormalities, or neurological or psychological illnesses. ${ }^{27}$ The NEL review found only "limited" or "insufficient" evidence that the diets could combat diabetes. ${ }^{42}$ In a highly unorthodox move, the guideline committee overruled the NEL's systematic reviews on this topic and decided to upgrade the rank to "moderate," based on its opinion that one review paper on observational data, which showed positive results, was particularly strong.

And are the recommended diets better than other diets in helping people lose weight? On this question, the report ranked the evidence as moderate, yet to support this claim, it presents only a single clinical trial in 180 people with metabolic syndrome, which found the Mediterranean diet produced more weight loss than a low fat diet. ${ }^{43}$ One randomized controlled trial listed by the review did not actually test weight loss, only the ability to adhere to the diet ${ }^{44}$ which, although important, is relevant only if the diet works. Three trials ${ }^{45-47}$ and an AHA/ACC review ${ }^{48}$ concluded that compared with other diets, those recommended by the dietary guidelines offered at best a marginal advantage in fighting obesity (less than a pound over trial periods lasting up to seven years).

The report also gave a strong rating to the evidence that its recommended diets can fight heart disease. ${ }^{27}$ Again, several studies are presented, but none unambiguously supports this claim. Eight trials reviewed by the NEL to support its strong grade include one trial that should not have been included because it lacked a comparable control group ${ }^{49}$; three that showed no beneficial effects on cardiovascular health other than improved blood pressure (and studied hypertensive populations) $)^{50-52}$; another, also in hypertensive people, showing that the recommended diet had poorer cardiovascular outcomes than other options that were higher in monounsaturated fat or protein ${ }^{53}$; one showing mixed results on cardiovascular risk factors (although low density lipoprotein cholesterol fell, so did "good" high density lipoprotein cholesterol) $)^{54}$; and the largest one, which concluded that the diet was ineffective for reducing cardiovascular risk. ${ }^{11}$ The committee also cites an AHA/ACC review, but this paper examines trials already covered by the NEL review, so including them again amounts to double counting. ${ }^{8}$ The committee reviewed other, more recent studies but not using any systematic or predefined methods.

In conclusion, the recommended diets are supported by a minuscule quantity of rigorous evidence that only marginally supports claims that these diets can promote better health than alternatives. Furthermore, the NEL reviews of the recommended diets discount or omit important data. There have been at a minimum, three National Institutes of Health funded trials on some 50000 people showing that a diet low in fat and saturated fat is ineffective for fighting heart disease, obesity, diabetes, or cancer. ${ }^{461155-59}$ Two of these trials are omitted from the NEL review. The third trial is included, but its results are ignored. This oversight is particularly striking because this trial, the Women's Health Initiative (WHI), was the largest nutrition trial in history. ${ }^{556}$ Nearly 49000 women followed a diet low in fat and high in fruits, vegetables, and grains for an average of seven years, at the end of which investigators found no significant advantage of this diet for weight loss, diabetes, heart disease, or cancer of any kind. ${ }^{1156-59}$ Critics dismiss this trial for various reasons, including the fact that fat consumption did not differ enough significantly between the intervention and control groups, but the percentage of calories from both fat and saturated fat were more than $25 \%$ lower in the intervention group than in the control group $(26.7 \% \vee 36.2 \%$ for total fat and $8.8 \% v 12.1 \%$ for saturated fats). ${ }^{57}$ The WHI findings have been confirmed by other sizeable studies and are therefore hard to dismiss. When the omitted findings from these three clinical trials are factored into the review, the overwhelming preponderance of rigorous evidence does not support any of the dietary committtee's health claims for its recommended diets.

A final area examined by The BMJ where the report offers advice that contradicts its data is on sodium. The committee says that it "concurs" with a recent report by the Institute of Medicine, which states that the evidence is "inconsistent and insufficient to conclude that lowering sodium intakes below $2300 \mathrm{mg} /$ day will have any effect on cardiovascular risk or

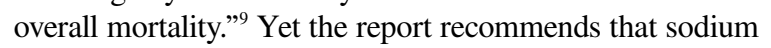
intake "should be less than $2300 \mathrm{mg} /$ day" and encourages the choice of low salt options without reservation.

\section{Questions about bias}

The overall lack of sound science and proper methods in the 2015 report could be seen as a reluctance to depart from existing dietary recommendations. Many experts, institutions, and industries have an interest in keeping the status quo advice, and these interests create a bias in its favor. Abandoning the NEL review methods, as the 2015 committee has done, opens the door not only for bias but also for influence from outside agendas and commercial interests, and all of these can be observed in the report.

For example, a bias towards the longstanding view that saturated fats are harmful can be seen in the report's designation of them, together with sugar, as a new category it calls "empty calories." The report repeatedly mentions the need to reduce "sugar and solid fats," because, "both provide calories, but few or no 
nutrients." ${ }^{2}$ Yet this pairing is unsupported by nutrition science. Unlike sugar, saturated fats are mostly consumed as an inherent part of foods such as eggs, meat, and dairy, which together contain nearly all of the vitamins and minerals needed for good health.

Not following the NEL methods has also allowed outside agendas to enter into the report, most clearly in the form of the new consideration for environmental sustainability. Although, as the report states, the environmental effects of food and drink production are considerable, they are outside the committee's formal mandate to provide the federal government with the "current scientific evidence on topics related to diet, nutrition, and health." In a new development for 2015, the USDA hired a food policy analyst focused on environmental issues to oversee the guideline committee's work, reflecting a new agenda in the process. $^{60}$

Much has been written about how industries try to influence nutrition policy, so it is surprising that unlike authors in most major medical journals, guideline committee members are not required to list their potential conflicts of interest. A cursory investigation shows several such possible conflicts: one member has received research funding from the California Walnut Commission $^{61}$ and the Tree Nut Council, ${ }^{62}$ as well as vegetable oil giants Bunge and Unilever. ${ }^{6364}$ Another has received more than $\$ 10000$ ( $£ 6400 ; € 8800$ ) from Lluminari, which produces health related multimedia content for General Mills, PepsiCo, Stonyfield Farm, Newman's Own, and "other companies." 65 And for the first time, the committee chair comes not from a university but from industry: Barbara Millen is president of Millennium Prevention, a company based in Westwood, MA, that sells web based platforms and mobile applications for self health monitoring. While there is no evidence that these potential conflicts of interest influenced the committee members, the report recommends a high consumption of vegetable oils and nuts as well as use of self monitoring technologies in programs for weight management.

Still, it's important to note that in a field where public research dollars are scarce, nearly all nutrition scientists accept funding from industry. Of far greater influence is likely to be bias in favor of an institutionalized hypothesis as well as a "white hat" bias to distort information for what is perceived as righteous ends. $^{66}$

The report is highly confident that its findings are supported by good science, stating that "The evidence base has never been stronger to guide solutions." " Millen told The BMJ, "You don't simply answer these questions on the basis of the NEL. Where we didn't feel we needed to, we didn't do them. On topics where there were existing comprehensive guidelines, we didn't do them. We used those resources and that time to cover other questions. The notion that every question that we posed should have a NEL is flawed." She said she would "go to the mat" to defend the committee's approach. "That's why you have an expert committee ... to bring expertise," including "our own original analyses."

"These folks know how to do this work. People who criticize this are coming from the point of view that they don't like the answer. They don't like the fact that randomised controlled trials testing these dietary patterns are successful. I think you have to read the report. NEL helped us to do the searches to do the update the literature. That is stated. If it doesn't satisfy you, that is all I can say. It's well stated and been reviewed by dozens of people."

On saturated fats, especially, she said, "We thought we nailed it." Millen said that her committee's work had not been entirely without methodology but had "worked with the NEL and USDA assistance to identify the research literature." She said that "it was clear that polyunsaturated fats reduced heart disease risk and mortality, yet that the "evidence is not as clear on whether replacement of saturated fat with monounsaturated fats or carbohydrates reduces cardiovascular disease risk, and likely depends on the type and source."

On diets low in carbohydrates, she said that there was "not substantial evidence" to consider. "Many popular diets don’t have evidence. But can you achieve healthiness, the answer is yes."

Regarding the committee's conflicts of interest, she said that members were vetted by counsel to the federal government. She would not reveal details of her company's activities. Critics of the report, she said, "are coming from the point of view that they don't like the answer."

Yet given the ever increasing toll of obesity, diabetes, and heart disease, and the failure of existing strategies to make inroads in fighting these diseases, there is an urgent need to provide nutritional advice based on sound science. It may be time to ask our authorities to convene an unbiased and balanced panel of scientists to undertake a comprehensive review, in order to ensure that selection of the dietary guidelines committee becomes more transparent, with better disclosure of the conflicts of interest, and that the most rigorous scientific evidence is reliably used to produce the best possible nutrition policy.

Competing interests: I have read and understood BMJ policy on declaration of interests and declare that I am the author of The Big Fat Surprise (Simon \& Schuster, 2014), on the history, science, and politics of dietary fat recommendations. I have received modest honorariums for presenting my research findings presented in the book to a variety of groups related to the medical, restaurant, financial, meat, and dairy industries. I am also a board member of a non-profit organization, the Nutrition Coalition, dedicated to ensuring that nutrition policy is based on rigorous science.

This article was fully funded with a grant from the Laura and John Arnold Foundation (www.arnoldfoundation.org). The analysis was conducted independently, and the report reflects the views of the author and not necessarily those of the foundation.

Provenance and peer review: Commissioned; externally peer reviewed and fact checked.

This article has been amended to update the urls for some of the references.

1 US Department of Agriculture. The food assistance landscape. 2015. https://www.ers. usda.gov/publications/pub-details/?pubid=44062.

2 Dietary Guidelines Advisory Committee. Scientific report. 2015. http://health.gov/ dietaryguidelines/2015-scientific-report/

3 Nutrition Evidence Library. Frequently asked questions. https://www.cnpp.usda.gov/ nutrition-evidence-library-about. \#Involvement

4 Dietary Guidelines Advisory Committee. Scientific report part C: methodology. Approaches to reviewing the evidence. http://health.gov/dietaryguidelines/2015-scientific-report/05methodology.asp.

5 Siri-Tarino PW, Sun Q, Hu FB, Krauss RM. Meta-analysis of prospective cohort studies evaluating the association of saturated fat with cardiovascular disease. Am J Clin Nutr 2010;91:535-46.

6 Siri-Tarino PW, Sun Q, Hu FB, Krauss RM. Saturated fat, carbohydrate, and cardiovascular disease. Am J Clin Nutr 2010;91:502-9.

7 Hooper L, Summerbell CD, Thompson R, et al. Reduced or modified dietary fat for preventing cardiovascular disease. Cochrane Database Syst Rev2012:5:CD002137.

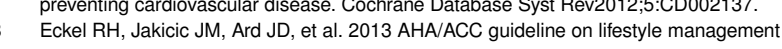
to reduce cardiovascular risk: a report of the American College of Cardiology/American Heart Association task force on practice guidelines. J Am Coll Cardiol2014;63:2960-84.

9 Dietary Guidelines Advisory Committee. Scientific report part D: chapter 6. Cross-cutting topics of public health importance — continued. http://health.gov/dietaryguidelines/2015scientific-report/11-chapter-6/d6-2.asp.

10 National Evidence Library. What is the effect of saturated fat intake on increased risk of cardiovascular disease or type 2 diabetes? https://www.cnpp.usda.gov/sites/default/files/ usda_nutrition_evidence_flbrary/2010DGAC-SR-FattyAcidsAndCholesterol.pdf.

11 Howard BV, Horn LV, Hsia J, et al. Low-fat dietary pattern and risk of cardiovascular disease: the Women's Health Initiative randomized controlled dietary modification trial. JAMA2006;295:655-66.

12 Farvid MS, Ding M, Pan A, et al. Dietary linoleic acid and risk of coronary heart disease: a systematic review and meta-analysis of prospective cohort studies. Circulation2014;130:1568-78. 


\section{What you need to know}

The latest dietary guidelines for Americans are imminent and will affect the diet of tens of millions of citizens, as well as food labeling, education, and research priorities. In the past most Western nations have adopted similar dietary advice

- The scientific committee advising the US government has not used standard methods for most of its analyses and instead relies heavily on systematic reviews from professional bodies such as the American Heart Association and the American College of Cardiology, which are heavily supported by food and drug companies. The committee members, who are not required to list their potential conflicts of interest, also conducted ad hoc reviews of the literature, without defining criteria for identifying or evaluating studies

- This year in its report to government, the committee largely sticks to the same advice it has given for decades-to eat less fat and fewer animal products and eat more plant foods for good health. But this decision to keep with the status quo fails to reflect much of the current, relevant science. Exceptions include a proposal for a cap on sugar intake

- The committee recommends three diets to promote better health, again without the accompanying rigorous evidence

- The US Congress has stepped in, with a hearing scheduled in October

13 Jakobsen MU, O'Reilly EJ, Heitmann BL, et al. Major types of dietary fat and risk of coronary heart disease: a pooled analysis of 11 cohort studies. Am J Clin Nutr2009;89:1425-32.

14 Chowdhury R, Warnakula S, Kunutsor S, et al. Association of dietary, circulating, and supplement fatty acids with coronary risk: a systematic review and meta-analysis. Ann Intern Med2014;160:398-406

15 Hooper L1, Summerbell CD, Thompson R, et al. Reduced or modified dietary fat for preventing cardiovascular disease. Cochrane Database Syst Rev2012;5:CD002137.

16 Siri-Tarino PW, Sun Q, Hu FB, Krauss RM. Meta-analysis of prospective cohort studies evaluating the association of saturated fat with cardiovascular disease. Am J Clin Nutr2010;91:535-46.

17 Mozaffarian D, Micha R, Wallace S. Effects on coronary heart disease of increasing polyunsaturated fat in place of saturated fat: a systematic review and meta-analysis of randomized controlled trials. PLoS Med2010;7:e1000252.

18 Skeaff CM, Miller J. Dietary fat and coronary heart disease: summary of evidence from prospective cohort and randomised controlled trials. Ann Nutr Metab2009;55:173-201.

19 Siri-Tarino PW, Sun Q, Hu FB, Krauss RM. Saturated fat, carbohydrate, and cardiovascular disease. Am J Clin Nutr 2010;91:502-9.

20 Leren P. The effect of plasma cholesterol lowering diet in male survivors of myocardial infarction: a controlled clinical trial. Acta Med Scand Suppl1966;466: 1-92.

21 Seymour D, Pearce ML, Hashimoto S, Dixon WJ, Tomiyasu U. A controlled clinical tria of a diet high in unsaturated fat in preventing complications of atherosclerosis. Circulation1969;40(suppl 2):1-63

22 Frantz ID, Dawson E, Ashman PL, et al. Test of effect of lipid lowering by diet on cardiovascular risk: the Minnesota coronary survey. Arterioscler Thromb Vasc Biol1989;1:129-35;

23 Turpeinen O, Karvonen M, Pekkarinen M, Miettinen M, Elosuo R, Paavilainen E. Dietary prevention of coronary heart disease: the Finnish Mental Hospital Study. Int J Epidemiol1979;2: 99-118.

24 Research Committee to the Medical Research Council. Controlled trial of soya-bean oil to the Medical Research Council. Lancet1968;2:693-9.

25 Multiple Risk Factor Intervention Trial Research Group. Multiple risk factor intervention trial: risk factor changes and mortality results. JAMA 1982;12:1465-77.

26 National Research Council, Food and Nutrition Board, National Academy of Sciences. Toward healthful diets. National Academy Press, 1980

27 Dietary Guidelines Advisory Committee. Scientific report part D: chapter 2. Dietary patterns, foods and nutrients, and health outcomes-continued. http://health.gov/dietaryguidelines/ 2015-scientific-report/07-chapter-2/d2-2.asp.

28 Feinman RD, Pogozelski WK, Astrup A, et al. Dietary carbohydrate restriction as the first approach in diabetes management: critical review and evidence base. Nutrition2015;31:1-13

29 Ajala O, English P, Pinkney J. Systematic review and meta-analysis of different dietary approaches to the management of type 2 diabetes. Am J Clin Nutr2013;97:505-16.

30 Santos FL, Esteves SS, da Costa Pereira A, Yancy WS Jr, Nunes JP. Systematic review and meta-analysis of clinical trials of the effects of low carbohydrate diets on cardiovascular risk factors. Obes Rev2012;13:1048-66.

31 Johnston BC, Kanters S, Bandayrel K, et al. Comparison of weight loss among named diet programs in overweight and obese adults: a meta-analysis. JAMA2014;312:923-33.

32 Bueno NB1, de Melo IS, de Oliveira SL, da Rocha Ataide T. Very-low-carbohydrate ketogenic diet v. low-fat diet for long-term weight loss: a meta-analysis of randomised controlled trials. Br J Nutr2013;110:1178-87.

33 Center for Nutrition Policy and Promotion. Dietary guidelines for Americans, 1980 TO 2000. www.health.gov/dietaryguidelines/1980_2000_chart.pdf.

34 Dietary Guidelines Advisory Committee. Scientific report: part B. Chapter 2: 2015 DGAC themes and recommendations: integrating the evidence. http://health.gov/dietaryguidelines 2015-scientific-report/04-integration.asp.

35 Hering G. Meat industry has a cow over US dietary guidelines. Guardian 2015 May 19 www.washingtonpost.com/blogs/wonkblog/wp/2015/01/07/why-the-governments-newdietary-guidelines-could-be-a-nightmare-for-the-meat-industry.

36 Jalonick MC, Neergaard L. Let them eat meat. Associated Press 2015 Jun 24. www. usnews.com/news/politics/articles/2015/06/24/republicans-push-back-against-proposeddietary-guidelines.

37 Nutrition Evidence Library. Meat: systematic review questions. https://www.cnpp.usda. gov/sites/default/files/usda nutrition evidence flbrary/2010DGAC-SR-Protein.pdf

38 Estruch R, Ros E, Salas-Salvadó J, et al. Primary prevention of cardiovascular disease with a Mediterranean diet. N Engl J Med2013;368:1279-90.

39 Dietary Guidelines Advisory Committee. Scientific report: part D. Chapter 1. http://health gov/dietaryguidelines/2015-scientific-report/06-chapter-1/.

40 Nutrition Evidence Library. How do the health outcomes of a vegetarian diet compare to that of a diet which customarily includes animal products? https://www.cnpp.usda.gov/ sites/default/files/usda_nutrition_evidence_flbrary/2010DGAC-SR-Protein.pdf.

41 Nutrition Evidence Library. Vegetables/fruit: systematic review questions. https://www. cnpp.usda.gov/sites/default/files/usda_nutrition_evidence_flbrary/2010DGAC-SREnergyBalance.pdf.

42 Nutrition Evidence Library. What is the relationship between adherence to dietary guidelines/recommendations or specific dietary patterns, assessed using an index or score, and risk of type 2 diabetes? https://www.cnpp.usda.gov/sites/default/files/usda nutrition evidence flbrary/DietaryPatternsReport-FullFinal.pdf.

43 Esposito K, Marfella R, Ciotola M, et al. Effect of a Mediterranean-style diet on endothelial dysfunction and markers of vascular inflammation in the metabolic syndrome: a randomized trial. JAMA2004;292:1440-6.

44 Jacobs DR Jr, Sluik D, Rokling-Andersen MH, Anderssen SA, Drevon CA. Association of 1-y changes in diet pattern with cardiovascular disease risk factors and adipokines: results from the 1-y randomized Oslo Diet and Exercise Study. Am J Clin Nutr2009;89:509-17.

45 Estruch R1, Martínez-González MA, Corella D, et al. Effects of a Mediterranean-style diet on cardiovascular risk factors: a randomized trial. Ann Intern Med2006;145:1-11.

46 Howard BV, Manson JE, Stefanick ML, et al. Low-fat dietary pattern and weight change over 7 years: the Women's Health Initiative Dietary Modification Trial. JAMA2006;295:39-49.

47 Blumenthal JA, Babyak MA, Sherwood A, Craighead L, et al. Effects of the dietary approaches to stop hypertension diet alone and in combination with exercise and caloric restriction on insulin sensitivity and lipids. Hypertension 2010;55:1199-205.

48 Jensen MD, Ryan DH, Apovian CM, et al. 2013 AHA/ACC/TOS guideline for the management of overweight and obesity in adults: a report of the American College of Cardiology/American Heart Association Task Force on Practice Guidelines and The Obesity Society. J Am Coll Cardiol2014:63:2985-3023.

49 Adamsson V1, Reumark A, Fredriksson IB, et al. Effects of a healthy Nordic diet on cardiovascular risk factors in hypercholesterolaemic subjects: a randomized controlled trial (NORDIET). J Intern Med2011;269:150-9.

50 Appel LJ, Moore TJ, Obarzanek E, et al. A clinical trial of the effects of dietary patterns on blood pressure. DASH Collaborative Research Group. N Engl J Med1997;336:1117-24.

51 Sacks FM, Svetkey LP, Vollmer WM, et al. Effects on blood pressure of reduced dietary sodium and the dietary approaches to stop hypertension (DASH) diet. DASH-Sodium Collaborative Research Group. N Engl J Med2001;344:3-10.

52 Margetts BM, Beilin LJ, Armstrong BK, Vandongen R. A randomized control trial of a vegetarian diet in the treatment of mild hypertension. Clin Exp Pharmaco Physiol1985;12:263-6.

53 Appel LJ, Sacks FM, Carey VJ, et al. Effects of protein, monounsaturated fat, and carbohydrate intake on blood pressure and serum lipids: results of the OmniHeart randomized trial. JAMA2005;294:2455-64.

54 Obarzanek E, Sacks FM, Vollmer WM, et al. Effects on blood lipids of a blood pressure-lowering diet: the Dietary Approaches to Stop Hypertension (DASH) Trial. Am $J$ Clin Nutr2001;74:80-9.

55 Walden CE, Retzlaff BM, Buck BL, et al. Differential effect of national cholesterol education program (NCEP) step II diet on HDL cholesterol, its subfractions, and apoprotein Al levels in hypercholesterolemic women and men after 1 year: The beFIT Study. Arterioscler Thromb Vasc Biol 2000;20:1580-7

56 Beresford SAA, Johnson KC, Ritenbaugh C, et al. Low-fat dietary pattern and risk of colorectal cancer: the Women's Health Initiative Randomized Controlled Dietary Modification Trial. JAMA2006;295:643-54

57 Knopp RH, Walden CE, Retzlaff BM, et al. Long-term cholesterol-lowering effects of 4 fat-restricted diets in hypercholesterolemic and combined hyperlipidemic men. the dietary alternatives study. JAMA1997;278:1509-15. https://www.ncbi.nlm.nih.gov/pubmed/9363971

58 Prentice RL, Caan B, Chlebowski RT, et al. Low-fat dietary pattern and risk of invasive breast cancer: the Women's Health Initiative randomized controlled dietary modification trial. JAMA2006;295:629-42.16467232

59 Prentice RL, Thomson CA, Caan B, et al. Low-fat dietary pattern and cancer incidence in the Women's Health Initiative dietary modification randomized controlled trial. J Natl Cancer Inst2007;99:1534-43.17925539

60 Harrington E. USDA hires environmentalist food activist to oversee dietary guidelines. Washington Free Beacon 2015 Jun 10. http://freebeacon.com/issues/usda-hiresenvironmentalist-food-activist-to-oversee-dietary-guidelines/.

61 Kris-Etherton PM, Hu FB, Ros E, Sabaté J. The role of tree nuts and peanuts in the prevention of coronary heart disease: multiple potential mechanisms. J Nutr2008;138:1746-51S.

62 Bao Y, Han J, Hu FB, et al. Association of nut consumption with total and cause-specific mortality. N Engl J Med2013;369:2001-11.

63 Shi Y, Hu FB. The global implications of diabetes and cancer. Lancet 2014;383:1947-8.

64 Mozaffarian D, Hao T, Rimm EB, Willett WC, Hu FB. Changes in diet and lifestyle and long-term weight gain in women and men. N Engl J Med 2011;364:2392-404.

65 Herman J. Saving US dietary advice from conflicts of interest. Food Drug Law J 2010;65:285-316.

66 Cope MB, Allison DB. White hat bias: examples of its presence in obesity research and a call for renewed commitment to faithfulness in research reporting. Int $\mathrm{J}$ Obes2010;34:84-8.

Cite this as: $B M J 2015 ; 351: \mathrm{h} 4962$ 


\section{Related links}

\section{thebmj.com}

- Visit our diet speciality page
- Editorials: Where the latest US dietary guidelines are heading (BMJ 2015;351:h4034)

๑ BMJ Publishing Group Ltd 2015 